\title{
Bacterial susceptibility patterns to cotrimoxazole in urinary tract infections of outpatients and inpatients in Jakarta, Indonesia
}

\author{
Yeva Rosana, ${ }^{1}$ Dwiana Ocviyanti, ${ }^{2}$ Wafridha Akbar $^{3}$
}

Check for updates

pISSN: 0853-1773 • elSSN: 2252-8083 https://doi.org/10.13181/mji.oa.204305 Med J Indones. 2020;29:316-21

Received: March 11, 2019

Accepted: June 22, 2020

Authors' affiliations:

'Department of Microbiology, Faculty of Medicine, Universitas Indonesia, Cipto Mangunkusumo Hospital, Jakarta, Indonesia, ${ }^{2}$ Department of Obstetrics and Gynecology, Faculty of Medicine, Universitas Indonesia, Cipto Mangunkusumo Hospital, Jakarta, Indonesia, ${ }^{3}$ Faculty of Medicine, Universitas Indonesia, Jakarta, Indonesia

\section{Corresponding author:}

Yeva Rosana

Department of Microbiology, Faculty of Medicine, Universitas Indonesia, Cipto Mangunkusumo Hospital, Jalan Pegangsaan Timur No. 16, Pegangsaan, Menteng, Central Jakarta 10320, DKI

Jakarta, Indonesia

Tel/Fax: +62-21-31922850/

$+62-21-3100810$

E-mail: yeva.rosana@ui.ac.id

\begin{abstract}
BACKGROUND Cotrimoxazole, which has been one of the drugs of choice for urinary tract infections (UTIs) since 1960, must be evaluated to determine whether it is still a relevant drug for this use. This study aimed to assess the susceptibility patterns to cotrimoxazole of the bacteria that cause UTIs from urine samples of female outpatients (community-acquired [CA]-UTI) and inpatients (hospital-acquired [HA]-UTI) in Jakarta.
\end{abstract}

METHODS This study was conducted from December 2014 to December 2015. Susceptibility testing of bacteria causing UTIs was conducted on 27 of 311 female outpatient urine samples collected from six clinics in Jakarta, and secondary data susceptibility testing was performed on 27 of 107 urine samples of inpatients from hospitals in Jakarta. These samples were examined in the Clinical Microbiology Laboratory, Faculty of Medicine, Universitas Indonesia, Cipto Mangunkusumo Hospital.

RESULTS Susceptibility to cotrimoxazole was reported in $83 \%$ of the bacteria causing UTIs in CA-UTI and $44 \%$ of the bacteria in HA-UTI patients. Klebsiella pneumoniae was the most common cause of CA-UTI, with all isolates susceptible to cotrimoxazole (100\%). Conversely, Escherichia coli was the most common cause of HA-UTI but was only susceptible in some isolates (44\%). Bacteria from CA-UTI patients were almost twice as susceptible to cotrimoxazole compared with HA-UTI patients $(p=0.003)$.

CONCLUSIONS Based on the susceptibility patterns identified, cotrimoxazole can be used as a treatment for CA-UTI but not for HA-UTI patients in Jakarta, Indonesia.

KEYWORDS cotrimoxazole, inpatients, outpatients, urinary tract infections
Urinary tract infections (UTIs) are more common in women than in men, with a bacteriuria prevalence of $1-3 \%$ in women; conversely, the prevalence in males is only approximately $0.1 \% .{ }^{1}$ Women aged $16-35$ years old have a 35 times greater risk of having UTIs compared with men. ${ }^{2}$ UTIs can occur in both inpatients and outpatients. A study in Kuwait in $2008^{3}$ reported that the prevalence of UTIs was $15.7 \%$ in outpatients and $10.9 \%$ in inpatients. UTIs are the second most common cause of bacteremia in the hospital and account for as much as 35\% of nosocomial infections. ${ }^{4}$
Cotrimoxazole, which is the combination of trimethoprim and sulfamethoxazole, has been a first-line UTI therapy since 1960. Cotrimoxazole works by inhibiting the synthesis of tetrahydrofolic acid through the inhibition of two enzymatic reactions. Cotrimoxazole is effective against most Enterobacteriaceae, Staphylococcus sp., and Streptococcus sp. ${ }^{5}$ Cotrimoxazole is included on the list of National Essential Medicines 2013 as an antibacterial and is still used to treat UTIs in Indonesia, both for nosocomial and community UTIs and for UTIs that occur in pregnant women in their second 
trimester. ${ }^{6,7}$ However, recently, the bacteria that cause UTIs have displayed a decreased susceptibility to cotrimoxazole in various regions of the world. According to the Antimicrobial Resistant Study in Indonesia (AMRIN-study), bacterial susceptibility to an antibiotic began to decrease in hospitals, and now this decrease in susceptibility has begun to appear in the community. ${ }^{8}$ Bacterial susceptibility pattern data from the Clinical Microbiology Laboratory, Faculty of Medicine, Universitas Indonesia-Cipto Mangunkusumo Hospital showed that $42 \%$ of Escherichia coli in hospitalized patients were resistant to cotrimoxazole. ${ }^{9}$ Cotrimoxazole resistance rates were reported $44.7 \%$ of inpatients and $33.2 \%$ of outpatients in a hospital in the city of Santa Cruz do Sul in Brazil. ${ }^{10}$

Based on the 2014 European Association of Urology guidelines, ${ }^{11}$ cotrimoxazole can only be used as the main therapy for empirical UTIs if the susceptibility to E. coli, the most common cause of UTIs, is $>80 \%$ in an area including the community (outpatient) and hospital (inpatient). Several studies in Indonesia reported that even though the susceptibility to cotrimoxazole was less than $80 \%$, cotrimoxazole was still used to treat UTIs. Therefore, it is necessary to evaluate whether cotrimoxazole remains suitable for use as UTI therapy in Indonesia for inpatients, outpatients, or both.

\section{METHODS}

This cross-sectional study was a collaboration between the Department of Microbiology and Obstetrics Gynecology, Faculty of Medicine, Universitas Indonesia, Cipto Mangunkusumo Hospital, Jakarta. This study was approved by the Ethical Committee of the Faculty of Medicine, Universitas Indonesia (No: 896/UN2.F1/ETIK/2014). Susceptibility patterns for outpatients were analyzed as the primary outcomes whereas those for inpatients were the secondary outcomes.

The primary source of data for outpatients was midstream urine samples obtained from six primary health centers (Puskesmas) in Jakarta that were collected using consecutive sampling techniques. The inclusion criteria for the outpatients were as follows: pregnant women who were willing to participate in the study by signing an informed consent form. The exclusion criteria were pregnant patients who had voiding symptoms and had used antibiotics 3 days before sampling. The secondary data were the results of the susceptibility testing of midstream urine cultures in inpatients who were examined at the Clinical Microbiology Laboratory, Faculty of Medicine, Universitas Indonesia, Cipto Mangunkusumo Hospital. There were two places to examine the bacterial culture in Cipto Mangunkusumo Hospital and this data limited to Clinical Microbiology Laboratory. Secondary data on the susceptibility to cotrimoxazole of UTI-causing bacteria in inpatients were obtained through the World Health Organization-net database of the Microbiology Laboratory, Faculty of Medicine, Universitas Indonesia-Cipto Mangunkusumo Hospital in 2014-2015. Figure 1 shows the subjects recruitment of this study.

\section{Clinical specimens}

This study was conducted from December 2014 to December 2015 in six primary health centers in DKI Jakarta: Pasar Rebo, Duren Sawit, Kramat Jati, Makasar, Pulo Gadung, and Cakung. Midstream specimen of urine samples were collected in sterile containers and tested via dipstick examinations. If the nitrite and/or leucocyte esterase results were positive according to the dipstick test, bacterial growth was examined by culturing at the Clinical Microbiology Laboratory, Faculty of Medicine, Universitas Indonesia, Cipto Mangunkusumo Hospital, Jakarta. The bacteria were cultured within a maximum period of 2 hours after urine sampling or on samples that had been stored at $2-8^{\circ} \mathrm{C}$ for a maximum of 24 hours.

\section{Culture}

Urine was cultured on blood and McConkey's agar medium for $18-24$ hours at $35-37^{\circ} \mathrm{C}$. Urine was transferred with a 0.001-ml loop and streaked in a line on the center of the agar medium. Then, a loop was scratched again in a direction perpendicular to the initial inoculum. The agar medium was incubated at $35-37^{\circ} \mathrm{C}$ for 18-24 hours. If the number of colonies exceeded $10^{5}$ colony forming unit (CFU)/ml, it was categorized as a UTI.

\section{Identification and susceptibility testing}

Identification and susceptibility testing were performed using the Vitek 2 system (bioMérieux, France). This method was performed according to the Clinical and Laboratory Standard Institute (CLSI) guidelines. The growing bacterial colonies were taken and placed into a test tube containing sterile saline 
( $0.45-0.50 \% \mathrm{NaCl}, \mathrm{pH} 4.5-7)$ to create a suspension. The turbidity of the suspension was adjusted according to the manufacturer's recommendations. Two types of cards were used, an identification card and a bacterial susceptibility test card. Vitex AST-GN316 was used to test the susceptibility of Gram-negative bacilli, and Vitex AST-GP67 was used to test the susceptibility of Gram-positive cocci. The test tubes were placed on a cassette, and the card was automatically filled by a vacuum device, sealed and inserted into the Vitek 2 reader-incubator module (incubation temperature, $35-37^{\circ} \mathrm{C}$ ), and subjected to a kinetic fluorescence measurement every $15 \mathrm{~min}$. The results of the bacteria identification and their susceptibility to antibiotics appear on the monitor screen after 3-7 hours. Bacterial samples were categorized as susceptible or resistant to cotrimoxazole according to the CLSI International standards (Figure 1).

\section{Statistical analysis}

The data were analyzed using SPSS software version 20 (IBM Corp., USA). The dependent variable in this study was the susceptibility of bacteria to cotrimoxazole (dichotomous nominal, susceptible, or resistant). The independent variables were outpatients and inpatients. Based on the sample formula of two independent groups, the minimum sample size in this study was 20 bacterial samples for each group. ${ }^{12}$ A bivariate analysis with the chi-square test was used to examine the significance of the susceptibility patterns to cotrimoxazole of the bacteria that cause UTIs in outpatients and inpatients. The results of data processing will produce a $p$-value that can be compared with the $\alpha(0.05)$ and confidence interval (95\%) values that have been previously determined. Statistical significance between the dependent and independent variables was determined using the $p$-value. The differences were considered significant when the $p$-value $<0.05$.

\section{RESULTS}

Of the 311 urine samples from outpatients, 27 (8.7\%) patients had positive culture results with $\geq 10^{5} \mathrm{CFU} / \mathrm{ml}$ of bacterial colonies causing UTIs. In the inpatients, 27 (25.2\%) positive culture results were obtained from 107

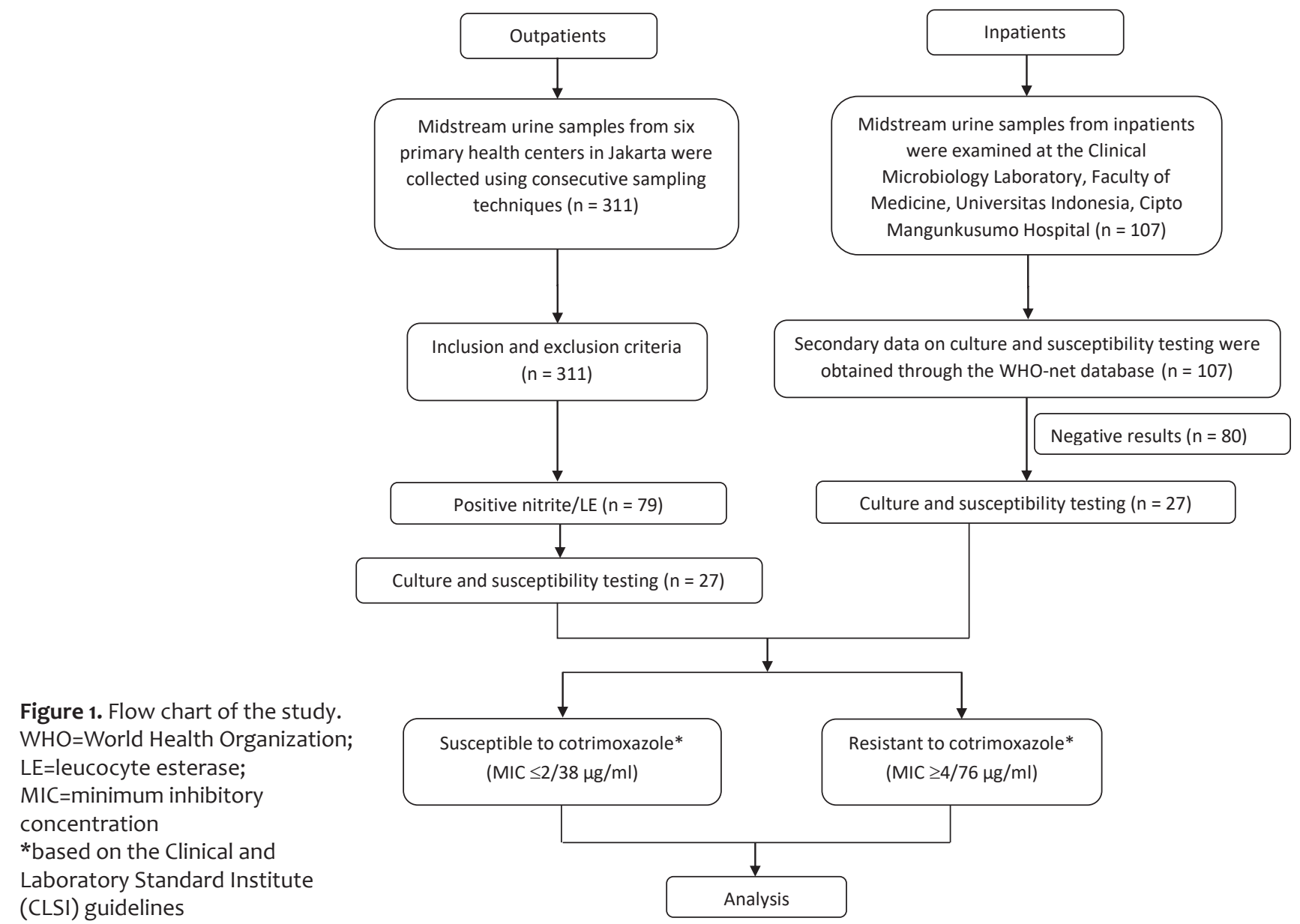

mji.ui.ac.id 
Table 1. Positive urine cultures in outpatients and inpatients

\begin{tabular}{|ccc}
\hline Urine samples & $\begin{array}{c}\text { Number of urine } \\
\text { samples, } \\
\mathrm{n}(\mathrm{N}=418)\end{array}$ & $\begin{array}{c}\text { Positive urine } \\
\text { cultures, } \\
\mathrm{n}(\mathrm{N}=54)\end{array}$ \\
\hline $\begin{array}{l}\text { Outpatients (primary } \\
\text { health center) }\end{array}$ & 311 & $27^{*}$ \\
\hline Makasar & 70 & $4^{*}$ \\
\hline Pasar Rebo & 70 & 5 \\
\hline Cakung & 29 & 3 \\
\hline Pulo Gadung & 73 & 6 \\
\hline Kramat Jati & 12 & 2 \\
\hline Duren Sawit & 57 & 7 \\
\hline Hospitalized patients & 107 & 27 \\
\hline
\end{tabular}

*Two of the urine samples from outpatients contained two bacterial isolates

urine samples. Details of the urine samples from the outpatient and inpatients are shown in Table 1.

Of the 27 positive urine cultures in outpatients, two urine samples were shown to contain two types of bacteria, then 29 bacterial samples were tested for susceptibility to cotrimoxazole. The cotrimoxazole susceptibility test results of all bacterial colonies cultured in outpatients showed that $83 \%$ (24 of 29 bacteria) were still sensitive to cotrimoxazole whereas $17 \%$ were resistant. Meanwhile, the bacterial susceptibility pattern from the urine of inpatients showed that $44 \%$ ( 12 out of 27 bacteria) of samples were still susceptible to cotrimoxazole and $56 \%$ were resistant. The susceptibility patterns to cotrimoxazole based on Gram-positive and Gram-negative bacteria that cause UTIs in outpatients and inpatients are shown in Figure 2. The susceptibility pattern of UTIcausing bacteria to cotrimoxazole indicated that

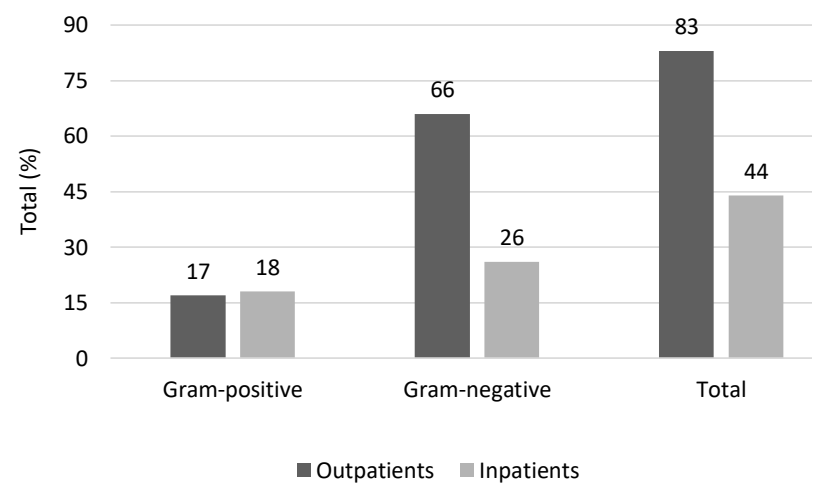

Figure 2. Susceptibility patterns of urinary tract infection (UTI)-causing bacteria to cotrimoxazole in outpatients $(n=27)$ and inpatients $(n=27)$
Table 2. Comparison of the susceptibility patterns of uropathogens to cotrimoxazole in outpatients and inpatients

\begin{tabular}{|c|c|c|c|}
\hline & \multicolumn{2}{|c|}{ Cotrimoxazole } & \multirow{2}{*}{$p^{*}$} \\
\hline & Susceptible, n (\%) & Resistant, n (\%) & \\
\hline Outpatients & $24(83)$ & $5(17)$ & 0.003 \\
\hline Inpatients & $12(44)$ & $15(56)$ & \\
\hline Total & 36 (64) & $20(36)$ & \\
\hline
\end{tabular}

*Chi-square test

outpatients were 1.86 times more susceptible than inpatients $(p=0.003)$ (Table 2).

All isolates of Klebsiella pneumoniae $(n=9 / 9,100 \%)$ in outpatients were susceptible to cotrimoxazole and only $57 \%(n=4 / 7)$ of E. coli were susceptible to cotrimoxazole. Meanwhile, $50 \%(n=1 / 2)$ of inpatients with $K$. pneumoniae infection and $44 \%(n=4 / 9)$ with $E$. coli infection were susceptible to cotrimoxazole.

\section{DISCUSSION}

To the best of our knowledge, susceptibility patterns to cotrimoxazole have been more reported in inpatients than outpatients. This study assessed the susceptibility of bacterial causes of UTIs in outpatients against cotrimoxazole and compared the results with inpatients. In the outpatients, $8.7 \%$ (27/311) of culture results supported a diagnosis of asymptomatic UTI (CA-UTI) that are similar to a study in Colombo (United States) in 2012, which reported that an average of $10 \%$ of pregnant women had UTIs. ${ }^{13}$ Santoso et al ${ }^{14}$ in 2017 also reported that the asymptomatic UTI prevalence in a population of pregnant women was 2-10\%. Among the inpatients, $25.2 \%$ (27/107) of the culture results supported a diagnosis of UTI (HA-UTI). This result is higher than that from surveillance conducted by Duerink et $\mathrm{a}^{15}$ in two teaching hospitals in Indonesia in 2006, who reported UTI prevalence rates of $0.9 \%$ and $3.5 \%$. This may be due to nosocomial events. Wilson et $\mathrm{al}^{4}$ reported $35 \%$ of nosocomial infections were UTIs, moreover $97 \%$ of UTIs in inpatients were related to catheters use.

The rate of bacterial susceptibility was 1.86 times higher in outpatients than in inpatients. This is similar to study in 2014 in Taiwan which stated that the susceptibility of bacteria that cause UTIs to cotrimoxazole is 1.4 times higher in outpatients (55.3\%) than in inpatients (38.7\%). ${ }^{16}$ The AMRIN study also states that the sensitivity of $E$. coli to 
cotrimoxazole in the community $(71 \%)$ is better than that in hospitals (44\%). ${ }^{8}$

K. pneumoniae is the most frequent bacterial cause of UTIs in outpatient women, and it showed a very good susceptibility pattern of $100 \%$. E. coli, the second most common cause of UTIs in outpatients in this study, showed a lower susceptibility. A study conducted in India in 2015 reported that the susceptibility to cotrimoxazole of K. pneumoniae was $88.9 \%$ and E. coli was $84.4 \%$ in outpatients. ${ }^{17}$ Another study in 2014 in Iraq showed the susceptibility of cotrimoxazole in $\mathrm{K}$. pneumoniae was $41.2 \%$ whereas it was $30.8 \%$ in E. coli. ${ }^{18}$

E. coli, the most common cause of UTIs in inpatients, showed an unfavorable susceptibility of only $44 \%$. The susceptibility of K. pneumoniae to cotrimoxazole also displayed unfavorable results. The susceptibility pattern of uropathogens to cotrimoxazole in 2015 was almost the same as that reported for inpatients from the Microbiology Laboratory, Faculty of Medicine, Universitas Indonesia, Cipto Mangunkusumo Hospital in 2012, with an E. coli susceptibility rate of $42 \%$ and a K. pneumoniae susceptibility rate of $56 \%{ }^{9}$

The cause of the low susceptibility of uropathogens to cotrimoxazole in inpatients could be determined by four factors: the use of antibiotics, the presence of resistant bacteria that cause UTIs, the lack of immunity in patients, and the hospital environment. In terms of antibiotic use, the decreased susceptibility may have been due to a previous history of failed UTI treatment, a history of recurrent UTIs, and irrational antibiotic use. The uncontrolled use of cotrimoxazole both in terms of dosage and duration also contributes to its low susceptibility. Incorrect initial diagnosis and high frequency of cotrimoxazole use as a therapy for both UTIs and other nosocomial infections will influence its' susceptibility. ${ }^{19}$ Moreover, the decreased susceptibility can be caused by genetic changes, such as carrying plasmids that are fused into bacterial chromosomes through transposons or integrons. ${ }^{20}$ In 2014, Toval et $\mathrm{al}^{21}$ reported that $E$. coli polygenetic types that cause UTIs in hospitalized patients have different variations from the bacteria causing these infections in outpatients in Germany. The E. coli that cause UTIs in hospitalized patients is a type of uropathogenic E. coli with or without a combination of one or more types of intraintestinal pathogenic E. coli (InPE). E. coli type InPE has three phylogroups: A, C, and B1, which play a role in causing resistance to multi-antibiotics. Next, the decline of bacterial susceptibility to an antibiotic was caused by the increasing use of invasive therapies such as catheters, the increasing disease severity, and immunocompromised status. ${ }^{22}$ Meanwhile, the lack of cleanliness and effectiveness of implementing hospital infection control programs caused a decrease of antibiotic susceptibility in inpatients..$^{22,23}$

In developing countries such as Indonesia, which has a high prevalence of UTIs, conducting bacterial susceptibility tests is quite expensive and requires a long period of time; consequently, UTI management is often given empirically. The empirical data used should be based on local bacterial susceptibility data. Unfortunately, the susceptibility to antibiotics changes over time and place.

This study demonstrates that the susceptibility pattern to cotrimoxazole in the community was good (83\%) indicating that cotrimoxazole can still be used for uncomplicated UTIs in outpatients in Indonesia. According to Infectious Disease Society of America guidelines, cotrimoxazole (160/800 mg) taken twice daily for 3 days is the therapy of choice for UTIs in women. ${ }^{11,25}$ Cotrimoxazole has a cure rate of $86.2 \%{ }^{26}$ It is cheap and easily available. Moreover, it is effective for a 3-day treatment period, which can increase patient compliance, reduce side effects, and reduce treatment costs. The side effects caused by cotrimoxazole were as low as UTIs therapy and only manifested as nausea, vomiting, and dizziness; no serious side effects occurred. A high sensitivity of cotrimoxazole in outpatients must be maintained by using it rationally, and being regulated based on the bacterial susceptibility pattern in the local area. Other efforts to prevent the spread of bacterial resistance from the hospital to the community include the monitoring of antibiotics locally, regionally, and nationally; recording and reporting cases of bacterial resistance; and providing complete management of antibiotics in cases of hospital infections.

The limitation of this study is the susceptibility of uropathogenic bacteria in inpatients was taken from secondary data. There were two places to examine the bacterial culture in Cipto Mangunkusumo Hospital and this data limited to Clinical Microbiology Laboratory. This study found that the susceptibility pattern of UTI-causing bacteria to cotrimoxazole was $83 \%$ in outpatients and $44 \%$ in inpatients. Thus, UTIcausing bacteria were almost twice as susceptible to cotrimoxazole in outpatients than in inpatients. These 
data indicate that cotrimoxazole can still be used to treat UTIs in outpatients, but it is not recommended for inpatients. This result can be used to help create guidelines for the rational use of cotrimoxazole in the treatment of acute UTIs in Indonesia, particularly in Jakarta.

\section{Conflict of Interest}

The authors affirm no conflict of interest in this study.

\section{Acknowledgment}

We would like to thank our colleagues, Melissa Halim, Friza Y Harlinda, Rahmah Amran, Matthew Billy, Syadza RP Akhmad, and seniors co-ass from Faculty of Medicine, Universitas Indonesia, Jakarta, for the collaborative cooperation in sample collection. We extend our deep appreciation to the team from the Department of Microbiology and Obstetrics Gynecology, Faculty of Medicine, Universitas Indonesia for technical assistance and support for this article.

\section{Funding Sources}

This study was funded by Zambon Indonesia. The authors declare that the supporting sources had no involvement with or influence on the content of the manuscript.

\section{REFERENCES}

1. Salvatore S, Salvatore S, Cattoni E, Siesto G, Serati M, Sorice P, et al. Urinary tract infections in women. Eur J Obstet Gynecol Reprod Biol. 2011;156(2):131-6.

2. Dielubanza EJ, Schaeffer AJ. Urinary tract infections in women. Med Clin North Am. 2011;95(1):27-41.

3. Al Benwan K, Al Sweih N, Rotimi VO. Etiology and antibiotic susceptibility patterns of community- and hospital-acquired urinary tract infections in a general hospital in Kuwait. Med Princ Pract. 2010;19(6):440-6.

4. Wilson ML, Gaido L. Laboratory diagnosis of urinary tract infections in adult patients. Clin Infect Dis. 2004;38(8):1150-8.

5. Katzung BG, Masters SB, Trevor AJ. Sulfonamide, trimethoprim, \& fluoroquinolones. In: Basic and clinical pharmacology. 11th ed. USA: McGraw-Hill Companies, Inc; 2009. p. 817-9.

6. Indonesian Ministry of Health. Decree of the Minister of Health of the Republic of Indonesia No. 312/MENKES/SK/IX/2013 about national list of essential medicines 2013. Jakarta [Indonesia]; 2013. Indonesian.

7. Ocviyanti D, Fernando D. Management and prevention of urinary tract infections in pregnancy. J Indon Med Assoc. 2012;62(12):482-6. Indonesian.

8. Duerink DO, Lestari ES, Hadi U, Nagelkerke NJ, Severin JA, Verbrugh HA, et al. Determinants of carriage of resistant Escherichia coli in the Indonesian population inside and outside hospitals. J Antimicrob Chemother. 2007;60(2):377-84.

9. Karuniawati A, Yulia RS, Budiyanti A, Prasetyo DS. Sensitivity to Gram negative bacteria originating from non-ICU patients. In: Results of tests of bacterial sensitivity to various antibiotics years; 2012. Jakarta: Clinical Microbiology Laboratory, Faculty of Medicine, Universitas Indonesia; 2012. p. 12. Indonesian.

10. Teichmann A, Agra HN, Nunes Lde S, da Rocha MP, Renner JD, Possuelo LG, et al. Antibiotic resistance and detection of the sul2 gene in urinary isolates of Escherichia coli in patients from Brazil. J Infect Dev Ctries. 2014;8(1):39-43.

11. Parsons KF, Poitiers JI, Fall M, Irani J, Llorente C, Loch T, et al. Urological infection. In: Association of Urology guidelines. Europe. EAU. 2014:832.

12. Madiyono B, Moeslichan S, Sastroasmoro S, Budiman I, Purwanto SH. Estimated sample size. In: Fundamentals of clinical research methodology. 4th ed. Jakarta: Sagung Seto; 2011. p. 348-81. Indonesian.

13. Bolton $M$, Horvath DJ Jr, Li B, Cortado H, Newsom D, White P, et al. Intrauterine growth restriction is a direct consequence of localized maternal uropathogenic Escherichia coli cystitis. PLoS One. 2012;7(3):e33897.

14. Santoso BI, Surya R, Yasmin FA, Irwinda R. The awareness of urinary tract infection management in pregnant women. A qualitative study. Majalah Obstet Ginekol. 2017;25(3):92-6.

15. Duerink DO, Roeshadi D, Wahjono H, Lestari ES, Hadi U, Wille $J C$, et al. Surveilance of healthcare-associated infections in Indonesian hospitals. J Hosp Infect. 2006;62(2):219-29.

16. Huang LF, Lo YC, Su LH, Chang CL. Antimicrobial susceptibility patterns among Escherichia coli urinary isolates from community-onset health care-associated urinary tract infection. J Formos Med Assoc. 2014;113(12):970-3.

17. Vachhani AV, Barvaliya $M$, Naik V, Jha P, Tripathi C. Effectiveness and tolerability of short course co-trimoxazole, norfloxacin and levofloxacin in bacteriological cure of uncomplicated urinary tract infection in outpatient setting. An open label, parallel group, randomized controlled trial. Infez Med. 2015;23(2):155-60.

18. Hussein NS. Clinical, etiology and antibiotic susceptibility profiles of community-acquired urinary tract infection in a Baghdad Hospital. Med Surg Urol. 2014;3(2):1000136.

19. Goldberg E, Bishara J. Contemporary unconventional clinical use of co-trimoxazole. Clin Microbiol Infect. 2012;18(1):8-17.

20. Sari PA, Erly, Arisanty D. Comparison of the Inhibitory effectiveness of generic and patented cotrimoxazole on the growth of Escherichia coli bacteria as a cause of urinary tract infection in vitro. J Kesehatan Andalas. 2015;3(1): 227-32. Indonesian.

21. Toval F, Köhler CD, Vogel U, Wagenlehner F, Mellmann A, Fruth A, et al. Characterization of Escherichia coli isolates from hospital inpatients or outpatients with urinary tract infection. J Clin Microbiol. 2014;52(2):407-18.

22. Irenge LM, Kabego L, Vandenberg O, Chirimwami RB, Gala JL. Antimicrobial resistance in urinary isolates from inpatients and outpatients at a tertiary care hospital in South-Kivu Province (Democratic Republic of Congo). BMC Res Notes. 2014;7:374.

23. Hsueh PR, Hoban DJ, Carmeli Y, Chen SY, Desika S, Alejandria $\mathrm{M}$, et al. Consensus review of the epidemiology and appropriate antimicrobial therapy of complicated urinary tract infections in Asia-Pasific region. J Infect. 2011;63(2):114-23.

24. Tantry BA, Rahiman S. Antibacterial resistance and trend of urinary tract pathogens to commonly used antibiotics in Kashmir Valley. West Indian Med J. 2012;61(7):703-7.

25. Gupta A, Hooton TM, Naber KG, Wullt B, Colgan R, Miller LG, et al. International clinical practice guidelines for the treatment of acute uncomplicated cystitis and pyelonephritis in women: a 2010 updated by the Infectious Disease Society of America and European Society for Microbiology and Infectious Diseases. Clin Infect Dis. 2011;52(5):e103-20.

26. Leblebicioglu H, Ozaras R, Sunbul M. Role of co-trimoxazole for urinary tract infections in developing countries. Lancet Infect Dis. 2015;15(7):764-5. 